\title{
Professionalism in Sudanese Medical Schools: A Situational Analysis as Perceived by Medical Graduates From 22 Medical Schools.
}

Mohamed A. M. lesa

Umm al-Qura University

Makarim Elfadil M. Osman

University of Khartoum

Mohamed Hassan Taha

University of Sharjah

Elmuntaser T. Salah

National Ribat University

Emadeldin Hassan. E. Konozy ( $\nabla$ ehkonozy@yahoo.com )

Africa City of Technology

Salwa E. Hussein

University of Gezira

Ahmed A Mohamedani

University of Gezira

\section{Research Article}

Keywords: Professionalism, Medical Graduates, Curricula, Professionalism Elements

Posted Date: March 2nd, 2021

DOl: https://doi.org/10.21203/rs.3.rs-237575/v1

License: (9) (i) This work is licensed under a Creative Commons Attribution 4.0 International License. Read Full License 


\section{Abstract}

Background: Professionalism is progressively recognized as an essential component of the medical profession. This study aims to measure the perception and definition of medical graduates on the domains of professionalism with correlation to the teaching strategies reported from 22 medical schools in Sudan.

Method: A cross-sectional study using quantitative and qualitative approaches was performed and covered 22 different medical schools in Sudan, with 500 graduates taking part in the study.

Results: 257 of the graduates who participated in this study were taught about professionalism either through formal ways were $175(68 \%)$ or by hidden curricula, 82 of participants (32\%). 29 of the graduates who were taught formally had further education about the subject in the clinical setting. Sudanese socialenvironmental culture is the major influence of professionalism perception among graduates. They preferred mixing both teacher-based and peer-based approaches that encourage interaction when teaching professionalism.

Conclusion: Currently there were a blend of approaches to teach professionalism in Sudanese medical schools, including formal and informal method. The details of the arrangement, deepness, elements, and nature by which to integrate professionalism with other curriculum elements remain an infant matter. This apparent deficiency requires immediate attention and cooperation between medical schools and health corporations and agencies across the country to provide a suitable model to teach professionalism at medical schools and in clinical settings.

\section{Introduction}

Sudan is a mixture of culture, conducts, principles and actions. Arabic is a formal language and Islam is the belief of the majority of the population. However, the Sudanese's behaviors and traditional practices are not necessarily stemmed only from Islamic principles; public morals have been recognized as standard amongst them too. The clear characteristics of medical professionalism in the Sudanese context is not available, and teaching of professionalism is not built on situational analysis, research, and perception of students in the Sudanese context. Hence, since professionalism is closely related to the social contract, graduates in Sudan may perceive professionalism different from other nations.

The idea that healers have a higher calling and greater need for personal integrity was stemmed from the ancient origin and was evolved [1, 2]. In modern days, the exact description of the standards that formulate medical professionalism remained vague and elusive. There are ongoing debates about the role of physicians and how education, training, regulation, and policies should maintain society's views with special consideration to the professional standards [2-4]. During the past decades, the awareness of the importance of professionalism among medical society was increased dramatically. Hence, many studies were aimed at identifying the fundamental principles of professionalism, their elements, the 
challenges associated with incorporating and teaching professionalism in medical schools, and the medical students' understanding and perception on the matter $[5,6]$.

Professionalism is a demonstration of respect, commitment, and respect. In other words, it's a person's attitude that reflects reasonable perceptions and practice [7-9]. The American Board of Internal Medicine (ABIM) stated that altruism, accountability, excellence, duty, integrity, and respect are to be construed as the elements of medical professionalism [10]. These attributions are widely used in different cultural settings worldwide as an acceptable template to outline and measure professionalism [10-14].

Professionalism is indeed an acquired state influenced by the surrounding environment rather than being an inherited trait [15]. Understanding the perception of Sudanese medical student on professionalism is currently lacking; especially that not all medical schools in the country teach professionalism or offer defined curricula in the subject and their moral code is highly influenced by the social and environmental settings which have micro-differences occurs between the different geographical areas of the country. However, there is a recent consensus among Sudanese education leaders at the Ministry of Higher Education, Scientific Research (MHER) and Sudan Medical Council (SMC) that teaching professionalism in Sudanese faculties of medicine should be prioritized with the aim at building professionalism curricula and providing explicit experience in professionalism $[16,17]$. In this situational study, we aim at identifying the concept of professionalism among Sudanese medical graduate, analyzing and measuring their perception of professionalism with correlation to the teaching strategies adopted by their respective medical schools, in order to shed light on the current status and provide insights that might help design a guideline for teaching professionalism to undergraduates in Sudan.

\section{Methods}

Study design. A cross-sectional study targeted medical graduates from all Sudanese colleges of medicine $(n=22)$ was conducted in August 2016. A total of 500 medical graduates who attended the annual workshop week that provide orientation for the graduates before embarking on their internship. This workshop is organized by Sudan Medical Council and the Ministry of Health were considered the sample size for this study.

Data collection. Quantitative and qualitative approaches were used to collect the data. The quantitative method was questionnaire-based designed to assess professionalism based on the graduates' perception. The data from the qualitative approach were collected by means of interviews and focus groups that were conducted in the training hall in the ministry of health, Khartoum, Sudan. Four administrative staff from the ministry of health and the Sudan medical council were present during the study period. The interviews and focus groups were arranged and done by the $1^{\text {st }}$ author, who has a PhD in Medical Education from the University of Gezira, Gazira, Sudan. All fresh graduates attended the precourse was selected as participants in this study and no one was declined to take part in the study. The authors in this investigation have a good knowledge of medical education and allied areas and they had no previous relationship with participants. Participants were aware that the professors who conducted this work are University teachers and they have been well-oriented about the aim, objectives and type of 
the research (i.e., situational study), and the content analysis for teaching professionalism in their schools. The guidelines of the study were thoroughly illustrated to participants and a pilot study was performed before the commencement of the focus groups sessions. Briefly, a combination of focus groups and one to one interview during the $3^{\text {rd }}, 4^{\text {th }}$, and $5^{\text {th }}$ days of the orientation were assembled and performed. Participants were distributed to three main groups (A, B and C). Each group had one leader to distribute chances between subgroups, while each subgroup has a prescriber who led one of five subgroups. Prescribers of subgroups were tasked to write discussion between members in the subgroup. The facilitator who is an expert senior medical educationist gathered the data and information written by each of five prescribers. Finally, the three facilitators reported to the researcher. The assemblies included three groups of 58 individuals each including one leader and five prescribers which were divided further into five subgroups each with 11 participants in 2 subgroups and 10 participants in the rest (Figure 1).

Data analysis. Simple descriptive statistics were used to compute the percentage values across the quantitative data set. While general deductive approach by the researcher was applied to analyze the qualitative data. Each group was facilitated by an expert medical educationist and one of the graduates was nominated as a leader and five other graduates as prescribers. All five facilitators were lecturers at different Sudanese faculties of medicine. Researcher was present during the focus groups. Interviews were designed to capture frank and specific visions, uninfluenced by the presence of peers from different Sudanese medical schools. A few individual interviews have been taken as well.

\section{Results}

Five-hundred medical graduates who attended the annual medical workshop orientation week in August; 2016 were subjected to this study. Only 483; 96.6\% (male (155) 1: 2.3 female (345)) responded to the questionnaires, 12 of which were excluded for either not mentioning the name of their medical school or for being graduated from out of Sudan. Around $54.6 \%$ (257) of the participants were introduced to professionalism in medical school either formally or through hidden curricula.

\section{Perception of professionalism:}

The 257 graduates who were offered any formal curriculum content related to professionalism and professional values were further investigated to determine the format of professionalism they had been taught and address their knowledge of professionalism's elements. Graduates who knew about professionalism through lectures and attended a course syllabus in medical school were about twice the number of those who knew about professionalism through informal ways ((174) 2.1: 1 (83)). And 61.9\% of them agreed in various degrees that formal teaching of the topic can equip them with basic knowledge. On the other hand, $57.6 \%$ of the graduates who knew about professionalism through informal means i.e. role model, or through training offered by healthcare centers; believed that incorporating professionalism courses in school is very important and of value (Figure 2).

\section{Professionalism curriculum:}


Among the 174 graduates who had explicit courses on professionalism were exposed to professionalism at medical school, two-thirds of the participants felt that the school curricula provided them with the major concepts of professionalism and encouraged teamwork. Furthermore, only 50 participants indirectly practiced the concept at healthcare centers and appreciated their usefulness. It's worth noting that some of the participants had described professionalism as medical ethics. Schools that didn't offer formal courses in the subject had a short course on medical ethics which was very appreciated by the participants $(73.5 \%)$.

A consensus definition of professionalism was established during the qualitative part of the study ( $n$, 174). It was not a reflection of any official definition commonly used in curriculums. But rather an inflexible established perception of what professionalism is, based on graduates' own culture and moral values, which is developed from cultural, religion and traditional Sudanese construct that blend together. The summary of their answer was "If we can't innately and inherently do the right thing, and realize what is right, then we can't imagine that 45 minutes to one-hour lecture on ethics is going to change someone's perception; especially as a Sudanese, if you don't have it by the time you reach medical school then lecture discussions will never fix it'. For the next round of discussion, the groups' $\mathrm{A}, \mathrm{B}$ and $\mathrm{C}$ were encouraged to provide a one-word answer to the following question, "when I say professionalism, what was the worst thing you have experienced during the teaching process? And when you hear professionalism what is quickly come across your mind?", the answer for each group was waste of time, nothing, fear respectively. Focusing on the group's $C$ negative answer, we found they believe that while it's vital to teach medical professionalism, it should be through informal means. As they consider learning professionalism standards can be through implication, connection with health professions, and own Sudanese moral code.

Upon investigating the other methods and means of teaching professionalism, the social missions and vision of the faculty and their values related to learning patient communication skills among those were taught about professionalism at their schools, we found that graduates strongly prefer group discussions as the best way to teach professionalism, they also favor this method in learning social mission and patients' communication skills. However, seminars that discuss professionalism vignette seem to be the less desirable means for teaching. But in general, using mixed teaching techniques (students and teachercentered) is advantageous for the teaching process of the three concepts (Table 1). The focus group interviews indicated that teacher encounter (i.e. role model) during the preliminary years is fundamental for teaching the theoretical knowledge about professionalism. Group A believes professionalism is acquired by education (lectures and classes) rather than participation and experience. On the other hand, group $C$ thinks professionalism which is taught through lectures doesn't prepare students for the real-life situation because it is a mora-oriented talk that doesn't allow for keen-sighted self-discussion. Interestingly, peer support and discussion are highly appreciated by the graduate for acquiring professionalism; "i.e. We regularly debrief and discuss moral and ethical dilemmas between sessions and on our breaks". Assessment of groups' perceptions about schooling, teaching approaches, and the evaluation and assessment techniques are summarized (Table 2). 
Table 1: The agreement of participants who were taught about professionalism at Med schools $(n, 257)$ on the methods of teaching A) Professionalism, B) faculty social missions and vision and C) patients' communication skills.

\begin{tabular}{|c|c|c|c|c|}
\hline \multicolumn{5}{|c|}{ A) Teaching methods vs, the concept of professionalism } \\
\hline & Field visits & Seminars & Assignments & Group discussion \\
\hline Strongly agree & $24.6 \%$ & $21.1 \%$ & $13 \%$ & $28.8 \%$ \\
\hline Agree & $21.1 \%$ & $25.5 \%$ & $20.7 \%$ & $24 \%$ \\
\hline Agree to some extent & $12.2 \%$ & $9.9 \%$ & $16.8 \%$ & $7.2 \%$ \\
\hline Don't agree & $3.9 \%$ & $5.2 \%$ & $10.8 \%$ & $1 \%$ \\
\hline Didn't answer & $38.2 \%$ & $33.3 \%$ & $38.7 \%$ & $39 \%$ \\
\hline \multicolumn{5}{|c|}{ B) Teaching methods vs social missions } \\
\hline & Field visits & Seminars & Assignments & Group discussion \\
\hline Strongly agree & $22.4 \%$ & $16.8 \%$ & $13.0 \%$ & $29.6 \%$ \\
\hline Agree & $25.5 \%$ & $29.6 \%$ & $24.4 \%$ & $28 \%$ \\
\hline Agree to some extent & $12.6 \%$ & $15.3 \%$ & $16.4 \%$ & $7.2 \%$ \\
\hline Don't agree & $7.5 \%$ & $6.4 \%$ & $13.9 \%$ & $2.5 \%$ \\
\hline Didn't answer & $32 \%$ & $31.9 \%$ & $32.3 \%$ & $31.9 \%$ \\
\hline \multicolumn{5}{|c|}{ C) Teaching methods vs communication skills } \\
\hline & Field visits & Seminars & Assignments & Group discussion \\
\hline Strongly agree & $35.2 \%$ & $9.7 \%$ & $17 \%$ & $30 \%$ \\
\hline Agree & $23.4 \%$ & $19.9 \%$ & $28.2 \%$ & $28.4 \%$ \\
\hline Agree to some extent & $8.3 \%$ & $20.5 \%$ & $16.6 \%$ & $8.3 \%$ \\
\hline Don't agree & $1.7 \%$ & $17.6 \%$ & $6.4 \%$ & $1.7 \%$ \\
\hline Didn't answer & $31.4 \%$ & $32.3 \%$ & $31.8 \%$ & $31.6 \%$ \\
\hline
\end{tabular}

Table 2: Summary of summary of Themes by prescriber of each group. 


\begin{tabular}{|c|c|c|}
\hline & & Themes \\
\hline \multirow[t]{2}{*}{ Schooling } & Group & $\begin{array}{l}\text { Do not recognize the legitimacy of somebody other than a doctor who is } \\
\text { familiar with clinical practice coaching to teaching them professionalism. }\end{array}$ \\
\hline & & $\begin{array}{l}\text { There is a differential opinion between specialties on the need for } \\
\text { professionalism (i.e. required by obstetricians, surges, GPs, etc. and less } \\
\text { needed by anesthetists). }\end{array}$ \\
\hline \multirow[t]{2}{*}{$\begin{array}{l}\text { Evaluation/ } \\
\text { Assessment }\end{array}$} & $\begin{array}{l}\text { Group } \\
\text { B }\end{array}$ & $\begin{array}{l}\text { Learn how to game the system on results of open-handed evaluations, } \\
\text { by writing what they trust their teachers want to get and what will give them } \\
\text { a good mark. }\end{array}$ \\
\hline & & $\begin{array}{l}\text { Have a little esteem for the methods in which professionalism has been } \\
\text { evaluated in their education packages. }\end{array}$ \\
\hline \multirow[t]{2}{*}{ Teaching } & $\begin{array}{l}\text { Group } \\
\mathrm{C}\end{array}$ & $\begin{array}{l}\text { Value the teaching of morals and the legal bounds in which they must } \\
\text { work. }\end{array}$ \\
\hline & & $\begin{array}{l}\text { Value the practical culture; detected as respectable proficient practice, } \\
\text { and perceived as the finest method (some view it as the only way) to learn } \\
\text { professionalism. }\end{array}$ \\
\hline
\end{tabular}

\section{Elements of professionalism:}

The elements of professionalism had been constructed and assessed based on the theocratical perception of the graduates. Essentially because of the mosaic culture, traditions, beliefs, and behaviors that constitute the participants' background, along with the different policies applied by the Sudanese medical schools, and the fact that the graduates had not practiced medicine yet. The majority of the partakers valued the professional practice of the five elements and contempt any behavior that goes against honor/integrity, altruism, and respect (Table 3).

Table 3: Elements of professionalism as perceived by Med school graduates (n, 257): 


\begin{tabular}{|c|c|c|c|c|c|}
\hline \multirow[t]{2}{*}{ Elements } & \multirow{2}{*}{$\begin{array}{l}\text { Tested questions for each element of } \\
\text { professionalism }\end{array}$} & \multicolumn{4}{|c|}{ Perception of each element (\%) } \\
\hline & & Agree & Disagree & $\begin{array}{l}\text { Don't } \\
\text { know }\end{array}$ & $\begin{array}{l}\text { Didn't } \\
\text { answer }\end{array}$ \\
\hline \multirow[t]{6}{*}{$\begin{array}{l}\text { Duty/ } \\
\text { Accountability }\end{array}$} & $\begin{array}{l}\text { a) Admits the wrong diagnosis before a } \\
\text { patient }\end{array}$ & 52.6 & 32.7 & 12.4 & 2.3 \\
\hline & $\begin{array}{l}\text { b) Will not leave before handing over } \\
\text { patients to the next colleague on duty }\end{array}$ & 91.9 & 4.3 & 2.1 & 1.7 \\
\hline & $\begin{array}{l}\text { c) Encourages patients to contribute on } \\
\text { decision making }\end{array}$ & 90.3 & 3.9 & 3.7 & 2.1 \\
\hline & $\begin{array}{l}\text { d) Discusses patients' cases with } \\
\text { colleagues in crowded places }\end{array}$ & 12.4 & 81.6 & 4.3 & 1.7 \\
\hline & $\begin{array}{l}\text { e) Calls insurance company to follow up } \\
\text { a valid patient claim }\end{array}$ & 44.1 & 21.3 & 31.7 & 2.9 \\
\hline & $\begin{array}{l}\text { f) Declines an invitation to an infection } \\
\text { control committee meeting }\end{array}$ & 12.8 & 72.7 & 11.8 & 2.7 \\
\hline \multirow[t]{5}{*}{$\begin{array}{l}\text { Excellence/ } \\
\text { Autonomy }\end{array}$} & $\begin{array}{l}\text { a) Reflects on clinical cases to discover } \\
\text { unmet learning needs }\end{array}$ & 84.5 & 10.8 & 3.7 & 1.0 \\
\hline & $\begin{array}{l}\text { b) Searches for best evidence available in } \\
\text { patient's care }\end{array}$ & 86.5 & 9.7 & 2.7 & 1.1 \\
\hline & $\begin{array}{l}\text { c) Collaborates with colleagues to draft } \\
\text { new hospital guidelines }\end{array}$ & 83.6 & 10.1 & 5.2 & 1.1 \\
\hline & $\begin{array}{l}\text { d) Invests part on income on attending } \\
\text { medical conferences }\end{array}$ & 61.9 & 21.9 & 14.7 & 1.5 \\
\hline & $\begin{array}{l}\text { e) Makes deals with pharma companies } \\
\text { to sponsor conferences }\end{array}$ & 26.1 & 38.1 & 33.3 & 2.5 \\
\hline \multirow[t]{5}{*}{$\begin{array}{l}\text { Honor/ } \\
\text { Integrity }\end{array}$} & $\begin{array}{l}\text { a) Gives wrong information to a patient to } \\
\text { protect a colleague }\end{array}$ & 5 & 57 & 32 & 7 \\
\hline & $\begin{array}{l}\text { b) Issues a false sick leave for a friend's } \\
\text { kid to study at home }\end{array}$ & 6 & 57 & 29 & 7 \\
\hline & $\begin{array}{l}\text { c) Changes actual data in research based } \\
\text { on supervisor's advice }\end{array}$ & 4 & 58 & 29 & 9 \\
\hline & $\begin{array}{l}\text { d) Hides information about fatal } \\
\text { diagnosis to avoid patient disturbance }\end{array}$ & 16 & 47 & 30 & 7 \\
\hline & $\begin{array}{l}\text { e) Introduces medical students as } \\
\text { doctors to patients }\end{array}$ & 23 & 42 & 28 & 7 \\
\hline \multirow[t]{2}{*}{ Altruism } & $\begin{array}{l}\text { a) Declines sports club to respond to an } \\
\text { emergency call }\end{array}$ & 90 & 6 & 1 & 3 \\
\hline & $\begin{array}{l}\text { b) Frequently skips clinical teaching to } \\
\text { prepare for a conference }\end{array}$ & 37 & 38 & 22 & 2 \\
\hline
\end{tabular}




\begin{tabular}{|c|c|c|c|c|c|}
\hline & $\begin{array}{l}\text { c) Cancels family appointments for } \\
\text { urgent patient's need }\end{array}$ & 86 & 4 & 7 & 3 \\
\hline & $\begin{array}{l}\text { d) Doesn't witness against hospital } \\
\text { employer in favor of a patient before court }\end{array}$ & 11 & 77 & 10 & 2 \\
\hline & $\begin{array}{l}\text { e) Turns down a home visit to a disable } \\
\text { patient due to busy clinic }\end{array}$ & 22 & 49 & 26 & 4 \\
\hline \multirow[t]{5}{*}{ Respect } & $\begin{array}{l}\text { a) Respects the roles of all members of } \\
\text { the healthcare team in the department }\end{array}$ & 94 & 2 & 1 & 3 \\
\hline & $\begin{array}{l}\text { b) Considers patient background when } \\
\text { explaining their clinical illness }\end{array}$ & 90 & 5 & 3 & 3 \\
\hline & $\begin{array}{l}\text { c) Keeps patients waiting at the clinic } \\
\text { without apology }\end{array}$ & 14 & 76 & 7 & 3 \\
\hline & $\begin{array}{l}\text { d) Gives priority to some patients based } \\
\text { on social status or nationality }\end{array}$ & 10 & 82 & 5 & 3 \\
\hline & $\begin{array}{l}\text { e) Criticizes a prescription written by a } \\
\text { colleague in front of patients. }\end{array}$ & 11 & 77 & 9 & 3 \\
\hline
\end{tabular}

\section{Discussion}

In Sudan, graduates' definition and perception of medical professionalism and its related elements are not driven from existing literature but rather from their social contract and moral values informed their environment that stemmed from multiple linguistics, ethnicity, religious, and cultural characteristics. Teaching and training professionalism is limited, hence, only half of the participants were familiar with the concept either by formal curricula and courses or through other informal ways. However, the percentage of graduates who were introduced to professionalism through formal courses are even low compared to any other finding from the western regions or even the middle east $[18,19]$. Of course, the topic of professionalism remained of interest to our graduates who are only familiar with the subject indirectly. The negative professionalism teaching experience group $\mathrm{C}$ mentioned during the interviews is probably because of the missing agreement on a definition, which is expected since there is the definition of professionalism remained to be vague and unclear, and there is still global debate on what professionalism should be [20]. Also, because the best methods to impart professional knowledge to students and faculty remained clearly in its infant stages and require deep attention. However, the consensus is that it's paramount to encourage professional behavioral characteristics and develop a professional identity [21, 22]. It was expected to find that graduates who were never taught about professionalism at their medical school could -yet had courses on medical ethics- perceive the two subjects as one. Studies showed that professionalism and ethics are indeed a construct and should always be taught together and introduced in one course within the medical curricula [23-25].

Learning about professionalism transpires from two different settings; medical schools and clinical training. In general, students believe that professionalism is "caught" and not "taught" [26]; hence, the 
majority of medical schools provide their students with long-term clinical experience and offer placements in different teaching hospitals [27]. Medical faculties in Sudan ably the same notion; consequently, our graduates believe professionalism to be most related to the clinical practice where they can directly interact with patients, colleagues, and other healthcare professionals. There is no doubt that a clinical setting can provide graduates (i.e. fresh doctors) with the environment to work in a team, allow them to interact with various specialties, and put them in real case-scenarios with patients and colleagues $[28,29]$. When it comes to medical school approaches to teach professionalism, communication skills, and social mission; graduates also lean toward the methods that are conceived as most interactive and problem-based where they can ably their judgment rather than being taught what to do. And they very much appreciate the mixed approach of peer communication and teaching-centered methods. It was suggested that one-directional formal moralistic learning customed by the curriculum without the experience and reflection provided by the multi-directional communications that involve teacher-student and student-student discussion, is not enough to make excellent doctors who exhibit professional characteristics [30]. The interview discussion with the graduates revealed that peer-support is a crucial constituent of professionalism, in which they learn a great deal about ethical support and develop their logic of professionalism through casual and informal dialogues and discussions. It is important to mention that participants who didn't learn about professionalism at medical schools acknowledged the influence of a role model "i.e. professor or tutor" in providing a picture of how professionalism should be. Careful consideration should be applied here, especially that the functional structure, culture, and the teacher's professionalism standards that constitute the hidden curricula may not always be positive [30-32].

The four-gates model of professionalism elements could be reflected on what the participants believe about professionalism. This model deals with self, tasks, others and god, which is applicable to societies with social values founded on faith like Sudan [33]. The western model for professionalism elements introduced by the American Board of Internal Medicine (ABIM), duty/accountability, excellence/autonomy, honor/integrity, altruism, and respect are widely accepted and used to measure professionalism in different settings and contexts [10,14,34]. All of these elements were valid in the context of Sudanese graduates. However, for eastern countries, this is not always true; for instance, testing these elements in the Persian context revealed that only excellence, integrity/honor, altruism, and respect are valid [35], while in Taiwan new element domains emerged such as commitment to care, righteous and rule-binding, the pursuit of patient quality care, etc. [36]. The cultural differences between east and west countries influence the definition, perception, and the construct of professionalism and how it is measured. This creates a great challenge for preparing curricula and setting the best practice to teach professionalism among medical students and new doctors, and since professionalism is multidimensional the steps for teaching it should be too. This can be achieved by setting the expectations, measuring and assesses, correcting the inappropriate behaviors and prevent them, and most importantly implementing cultural changes [37, 38].

\section{Conclusion}


This study offers a comprehensive description of Sudanese medical graduates' perceptions of medical professionalism based on elements that reflect the characteristics of medical professionalism defined by $A B I M$. The construct of professionalism is learnt by traditional formal didactic lectures in Sudanese medical schools. This is followed by clinical experience that provide the graduates with explicit formal and informal methods to learn and practice professionalism. The current efforts that recognize and promote professionalism in medical schools remain inadequate. Professionalism needs urgent attention in Sudanese medical schools' context. Graduates' perception reveals deficiencies in professional behavior aquired by negative role models and they are poorly offered real cases to learn professionalism experience. Although some schools have strict organized approach to teaching professionalism, many are not. Many schools do not provide instruction on the characteristics of a profession or the history and meaning of medical professionalism in the context of the current health care system in Sudan. There is no clear teaching methodology, or set of methodologies, that have demonstrated success in developing doctors with a higher degree of professionalism other than previous generation doctors who never had tought such curricula. As such, challenges of professionalism nowadays and graduates mass production mandate incorporation of medical professionalism curricula across medical schools.

\section{Declarations}

\section{Ethics approval and consent to participate}

This study was reviewed and approved by the ethical board at the faculty of medicine University of Gezira. All participants provided informed consent. The surveies were performed in accordance to the American Board of Internal Medicine (ABIM) guideline.

\section{Consent for publication}

Not applicable.

\section{Availability of data and materials}

Data from this study will be available upon request and will be provided by Dr. Mohamed A. M. lesa, Email: mohamedovi1@gmail.com.

\section{Competing interests}

Authors declare no competing interests.

\section{Funding}

The current research did not receive any funding.

\section{Authors' contributions}


Conception, analysis, interpetation and writing of the manuscript were conducted by MAMI, MEMO, and MHT. The data validation and manuscript editing were performed by ETS. Conseptualization of the project and supervision was done by ETS, SHE, EHEK and AAM. Writing and revision of the manuscript were done by all authors.

\section{Acknowledgements}

Authors would like to thank Dr. Mohamed M. Al-Eraky for his valuable insights, revising and editing the manuscript.

\section{References}

1] Jotterand F. The Hippocratic Oath and Contemporary Medicine: Dialectic Between Past Ideals and Present Reality? J Med Philo. 2005; 30:107-128, DOI:10.1080/03605310590907084

2] Hilton S, Southgate L. Professionalism in medical education. Teach Educ. 2007; 23:265-279.

3] Swick HM. "Toward a normative definition of medical professionalism". Acad Medicine. 2000; 75(6):612-6.

4] Starr P. The social transformation of American medicine. New York: Basic Book, 1982.

5] Adkoli BV, Al-Umran KU, Al-Sheikh M, Deepak KK, Al-Rubaish AM. Medical students' perception of professionalism: A qualitative study from Saudi Arabia. J Med Teach. 2011; 33(10):840-845. DOI:10.3109/0142159X.2010.541535.

6] Poni ES. The role of gross anatomy in promoting professionalism: a neglected opportunity! Clinical Anatomy (New York, N.Y.). 2006; 19(5):461-467. DOI: 10.1002/ca.20353.

7] Lindsay P, Norman DA. Human information processing: An introduction to psychology. Harcourt Brace Jovanovich, Inc., 1977.

8] Ponnamperuma G, Ker J, Davis M. Medical professionalism: teaching, learning and assessment. South East Asian J of Med Edu. 2012; 1:42-48

9] Mueller PS. Teaching and assessing professionalism in medical learners and practicing physicians. Rambam Maimonides Med J. 2015; 6(2): e0011. DOI:10.5041/RMMJ.10195

10] American Board of Internal Medicine. Physician Charter. ABIM Found, 2020, https://abimfoundation.org/what-we-do/physician-charter

11] Roberts LW, Green Hammond KA, Geppert CM, Warner TD. The positive role of professionalism and ethics training in medical education: a comparison of medical student and resident perspectives. Acad Psych. 2004; 28(3):170-82. 
12] Robins LS, Braddock $\mathrm{CH}$, Fryer-Edwards KA. Using the American Board of Internal Medicine's "Elements of Professionalism" for undergraduate ethics education. Acad Med J Assoc Am Med Coll. $2002 ; 77: 523-531$.

13] Symons AB, Swanson A, McGuigan D, Orrange S, Akl EA. A tool for self-assessment of communication skills and professionalism in residents. BMC Med Educ. 2009; 9:1.

14] Al-Eraky MM, Chandratilake M. How medical professionalism is conceptualized in Arabian context: A validation study. Med Teach. 2012; 34:90-95.

15] Hilton SR, Slotnick HB. Proto-professionalism: how professionalization occurs across the continuum of medical education. Med Edu. 2005; 39(1):58-65

16] Salih MAM, Swar MO. Professionalism in medicine and hyposkillia. Sudanese journal of Pediatrics. $2014 ; 14(1), 6$.

17] Karrar ZA. Professionalism and good medical practice: the role of Sudan Medical Council. Sudan Med J. 2009; 45(2), 1-4.

18] Sadat-Ali M. Professionalism: are we doing enough? Saudi Med J. 2004; 25(5):676-7

19] Ho MJ, Gosselin K, Chandratilake M, Monrouxe LV, Rees CE. Taiwanese medical student's narratives of intercultural professionalism dilemma: exploring tensions between western medicine and Taiwanese culture. Adv Health Sci Educ Theory Pract. 2017; 22(2):429-445. DOI: 10.1007/s10459-016-9738-x

20] Swick HM. Toward a normative definition of medical professionalism", Academic Medicine. 2000; 75(6):612-6.

21] Cruess RL, Cruess SR, Steinert Y. in: Cruess RL, Cruess SR, Steinert Y. (eds) "Teaching Medical Professionalism”. Cambridge Univ Press. 2009.

22] Cruess R, Mcllroy JH, Cruess S, Ginsburg S, Steinert $Y$. The Professionalism Mini-evaluation Exercise: a preliminary investigation. Acad Med J Assoc Am Med Coll. 2006; 81:74-78.

23] Graham Y. Essential Guide to Leading Your Team: How to Set Goals, Measure Performance and Reward Talent. New York: Pearson Education; 2013; p. 37-9

24] Mahajan R, Aruldhas BW, Sharma M, Badyal DK, Singh. Professionalism and ethics: A proposed curriculum for undergraduates. Int J Appl Basic Med Res. 2016; 6(3):157.

25] Stark P, Roberts C, Newble D, Bax N. Discovering professionalism through guided reflection. Med Teach. 2006; 28(1):25-31.

26] Huggett KN, Warrier R, Maio A. Early learner perceptions of the attributes of effective preceptors. Advances in Health Sciences Education: Theory Pract. 2008; 13(5):649-58. 
27] Rose GL, Rukstalis MR, Schuckit MA. Informal mentoring between faculty and medical students. Acad Med J Assoc Am Med Coll. 2005; 80:344-348.

28] Sadeghi R, Sedaghat MM, Sha-Ahmadi F. Comparison of the effect of lecture and blended teaching methods on students' learning and satisfaction. J Adv Med Educ Prof. 2014; 2(4):146-150.

29] Danaei SM, Zarshenas L, Oshagh M, Khoda MO. Which method of teaching would be better cooperative or lecture? Iranian J Med Edu. 2011; 11(1):24-31

30] Al-Eraky MM. Twelve tips for teaching medical professionalism at all levels of medical education. Med Teach. 2015; 37(11):1018-1025.

31] Azmand S, Ebrahimi S, Iman M, Asemani O. Learning professionalism through hidden curriculum: Iranian medical students' perspective. J Med Ethics. 2018; 11:10

32] Joynt GM, Wong WT, Ling L, Lee A. Medical students and professionalism: Do the hidden curriculum and current role models fail our future doctors. Med Teach. 2017; DOI: 10.1080/0142159X.2017.1408897

33] Al-Eraky MM, Donkers J, Wajid G, Van-Merrienbier JJG. A Delphi study of medical professionalism in Arabian countries: The four-gates model. Med Teach. 2014; 36:8-16.

34] Jahan F, Siddiqui MA, Al-Zadjali NM, Qasim R. Recognition of core elements for medical professionalism among medical students and faculty members. Oman Med J. 2016; 31(3):196-204

35] Aramesh $K$, Mohebbi M, Jessri M, Sanagou M. Measuring professionalism in residency training programs in Iran. Med Teach. 2009; 31(8):356-61.

36] Tsai TC, Lin C-H, Harasym PH, Violato C. Students' perception on medical professionalism: the psychometric perspective. Med Teach. 2007; 29:128-134.

37] Altirkawi K. Teaching professionalism in medicine: what, why and how? Sudan J Pardiatr. 2014; 14:31-38

38] Hodges B, Paul R, Ginsburg S, Ottawa Consensus Group Members. Assessment of professionalism: From where have we come to where are we going? An update from the Ottawa consensus group on the assessment of professionalism. Med Teach. 2019; 41(3):249-255

\section{Figures}




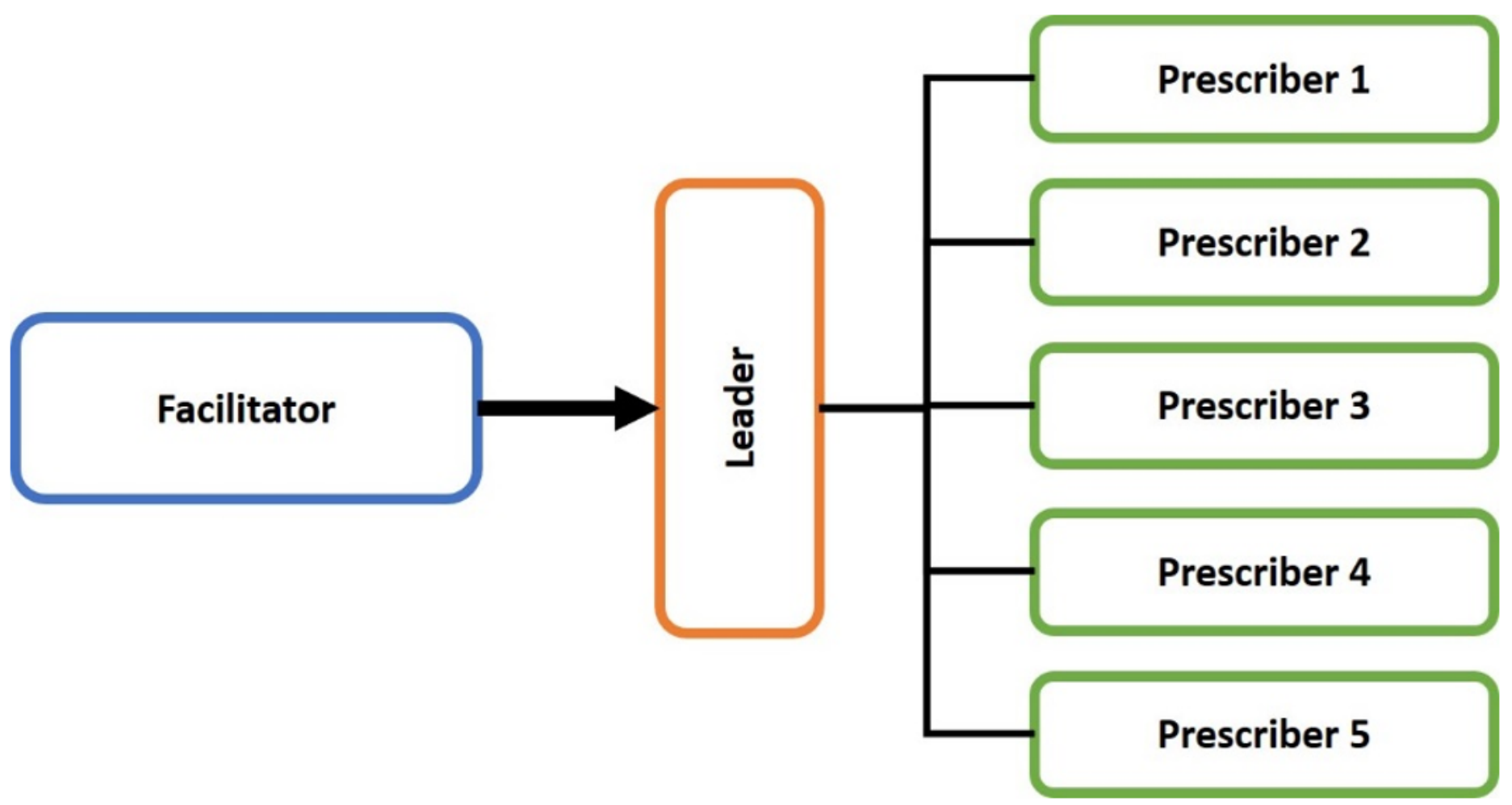

Figure 1

General scheme of each focus group assembled for the qualitative analysis 
A)

$35.0 \%$

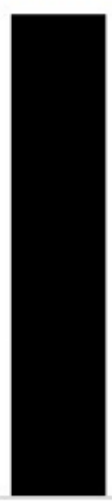

very imporant

B)
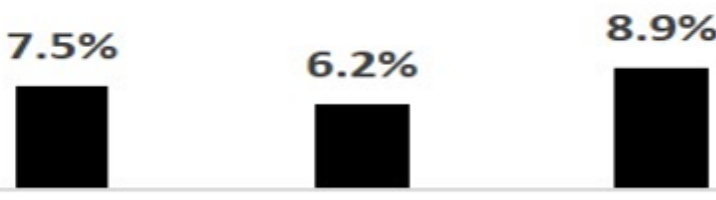

important

$6.2 \%$
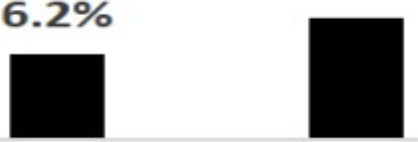

$1.0 \%$

Useful

Imporant \& useful

Didn't answer

$32.3 \%$

$25.3 \%$

$20.7 \%$

$15.9 \%$

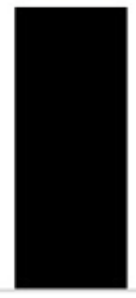

Strongly agree

Agree

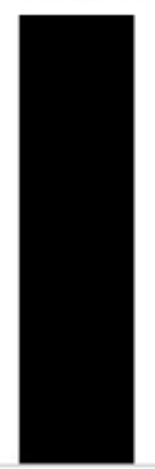

$5.8 \%$

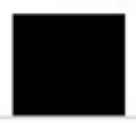

Agree to some

Don't agree extent

Figure 2

Opinion of graduates who were introduced to the concept of professionalism at medical school through explicit material or through informal means (n, 257): A) The opinion of graduates about the importance of incorporation of professionalism into the teaching materials in school $(n, 83)$. B) The agreement on teaching medical professionalism can equip graduates with the basic knowledge of the concept $(n, 174)$. 